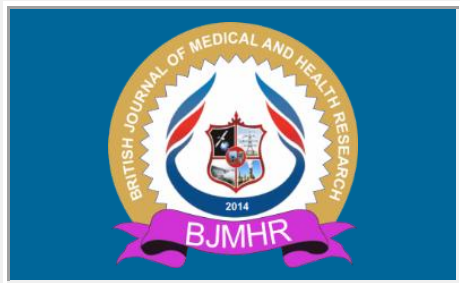

\title{
BJMHR
}

British Journal of Medical and Health Research

Journal home page: www.bjmhr.com

\section{A Review on Aerosols Dosage Form}

\section{Rajiv Kumar*, Manpreet Kaur Malhi, Japneet Singh, Simaranjot Singh, R.K. Dhawan \\ Khalsa College of Pharmacy, Amritsar}

\begin{abstract}
Aerosols are commonly used in the treatment of patient with pulmonary disease. The clinician must choose the appropriate aerosol delivery device. For both spontaneously breathing and mechanically ventilated patients, the first choice of device is usually the metered dose inhaler. There are important differences among devices in the dosage delivered to the lungs, for the typical prescription, nebulizers delivers more drug to the lungs than metered dose inhalers, which may be particularly important for acutely ill patients.
\end{abstract}

Keywords: Aerosols, Inhaler, Nebulizers, Propellant, Valves. 


\section{INTRODUCTION}

"An aerosol is a disperse phase system, in which very fine solid drug particles get dispersed in the propellants, which acts as continues phase." In aerosols are pressurized dosage forms containing one or more active ingredients which upon actuation emit a fine dispersion of liquid or solid material in a gaseous medium." Aerosol also called as a pressurized package because it is generally used for a therapeutically active drug. ${ }^{1}$ The term" aerosol "refers to the fine mist of spray that result from most pressurized systems. The advantages of aerosols are as follows:

- They are sterile and free from all contamination and used both local and systemic effect.

- If the product is packaged under sterile conditions, sterility may be maintained during shelf-life of the product.

- They are used directly to the affected area and they provide a cooling, refreshing effect.

- They are easy to use and apply without the help of others.

- Their action is faster as compared to other dosage forms.

- Some drugs are light sensitive's, so their container protects the drug from light ${ }^{2}$

The delivery of contents of aerosol depends on its valve assembly, container, and actuators as well as on the propellant. The two components of aerosol are product concentrate and propellant. The product concentrate contain the therapeutically active Ingredients. The propellant having vapour pressure greater than atmospheric pressure at $40^{\circ} \mathrm{c}$ is responsible for the development of proper pressure in the container to expel the product concentrate in the desired form like spray, mist, solid, foam, stream etc.

\section{Principle of Aerosols}

It is a system in which high velocity gas flow is directly into a tube that is immersed in a water reservoir. It operates from a pressurized gas. An aerosol formulation consists of two components parts, the product concentrate and the propellant showed in Figure 1. 


\section{Aerosols}

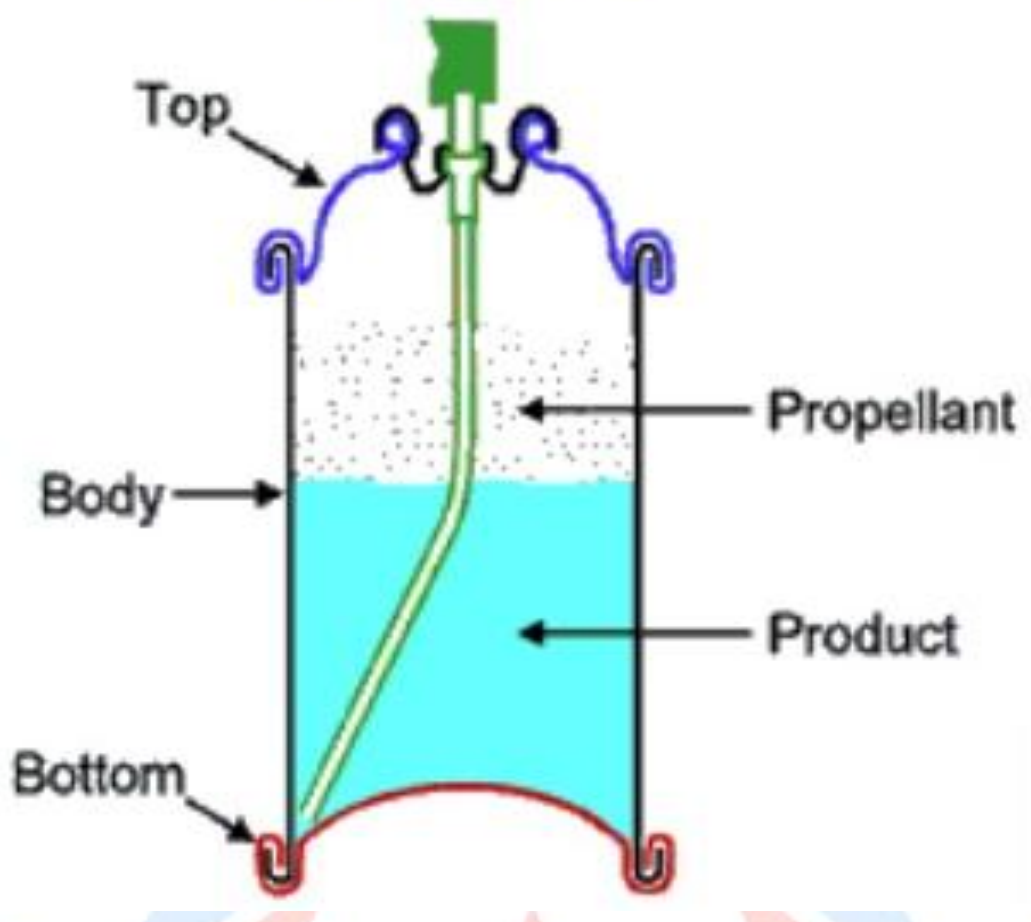

Figure 1: Principle of aerosol

Working mechanism:- As the gas flow through the tube, water is drawn up in between the surfaces and come across the way of gas flow through fine spores. Gas stream impacts upon the fluid surface and dispersing liquid as an aerosol. ${ }^{3-6}$

\section{Classification of Aerosols}

Space sprays: These products are delivered as a fine mist is called space spray. It contains $85 \%$ propellant and it is pressurized at $70^{\circ} \mathrm{F}$ with $30-40 \mathrm{psig}$. It contains not more than $50 \mu \mathrm{m}$ of particle. So it can be retaining in air. Eg: room deodorants and disinfectant.

Foam: Aerosols intended for carrying active ingredients to surface are termed as foam spray. These are produced by rapid expansion of propellants through an emulsion. Products come out in the form of froth. Eg: shaving cream. They are of different-2 types:

1.) Aqueous stable foams

2.) Non aqueous stable foams

Surface coats: They produce a wet coat when sprayed on a surface. It contains $30-70 \%$ propellant between $22-55$ psig at $70^{\circ} \mathrm{F}$.eg: hair spray and powder spray.

Inhaler: Inhalation is any dry drug or solution of a drug administered by the nasal or oral respiratory route. It is commonly to treat asthma and other respiratory problems. They are of 3 type's i.e.

1.) Pressurized metered dose inhaler (pMDIs)

2.) Dry powder inhalers (DPIs) 


\section{3.) Nebulizers}

\section{Pressurized metered dose inhaler (pMDIs):}

It is composed of canister, actuator, and spacer. Canister is composed of metering dose valve formulation (containing the active ingredients i.e. drug, a liquefied gas propellant and a stabilizers) present in canister. Upon actuator, the meter dose valve is opened which releases a single metered dose. This process is called cavitation. ${ }^{7-10}$ The liquefied gas propellant is volatile in nature, breakdown into liquid droplets which evaporates rapidly There are some of drawbacks of metered dose delivery are as follows:

A.) As pMDIs is pressurized, it emits the dose at high velocity and get deposited in the oropharynx.

B.) A careful coordination of actuation and inhalation are required.

C.) High chances of pharyngeal depositions.

\section{Dry powder inhaler (DPIs):}

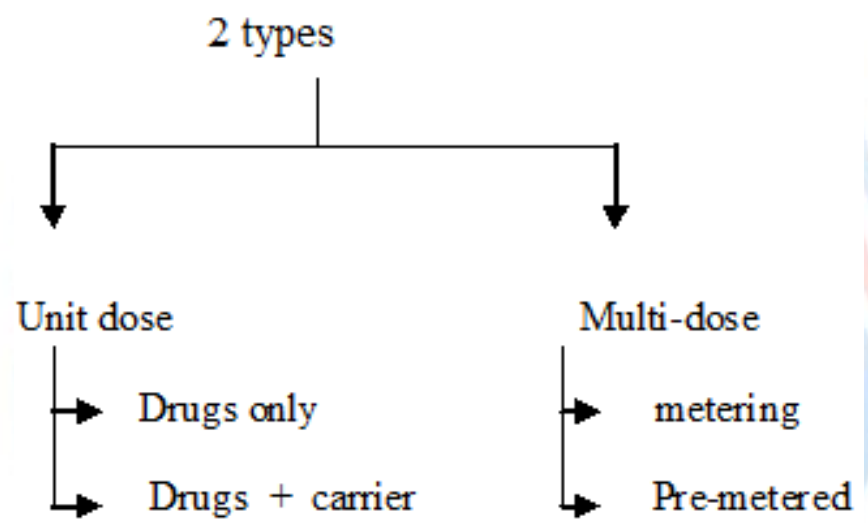

Unit dose: Unit dose are re-usable or disposable single dose dry powder inhaler. They are easy to use and suitable for wide range of conditions requires a rapid onset of effect. In this doses, the capsule shall is opened and the powder is inhaled by the user. Their advantage is that the unit dose cannot provide large dose in case of the asthma attack. Eg:- The innova ${ }^{\mathrm{TM}}$ (inhale therapeutic systems: San carlas, U.S.A.) is a long term used unit dose dry powder. Inhaler placed in a transparent holding chamber consisting of a stored bolus of compressed air which generate aerosol.

Multi- dose: Turbuhaler was first developed multi-dose DPIs by A.S Draco capable of delivery carrier free particles at moderate flow rates. Turbuhaler was replaced by dishaler developed by glaxosmith. DISHALER was used to deliver a variety of drug including salbutamol, baclomethasone. This is uses a circular disk containing four or eight powder doses that are maintained in separate aluminium blister reservior. 
Nebulizers: Nebulizer is used to administer a medication in the form of a mist inhaled through the lung. They are used for oxygen, compressed air or ultrasonic power to break up dose solution and suspension into small aerosol droplets called mists. They are directly inhaled through the mouth. ${ }^{11}$ Advantages of nebulizers are as follows:

- High dose is possible.

- They are easy to use

- No chlorofluorocarbon (CFC) is released.

- They are faster delivery, smaller and more portable.

The disadvantages of nebulizers are as follows:

- They are expensive.

- There is a chance of contamination.

- They cannot be aerosolized properly.

- Jet nebulizers require pressurized form of gas.

\section{COMPONENTS OF AEROSOLS}

- Propellant

- Container

- Valve and actuator

- Product concentrate

\section{Propellant}

Responsible for developing proper pressure within the container. They provide driving force to expel the product from the container. When the propellant is a liquefied gas or a mixture of liquefied gases, it frequently serves the dual role of propellant and solvent or vehicle for the product concentrate. In certain aerosol systems, no liquefied compressed gases, no carbon dioxide, nitrogen are employed as the propellant ${ }^{12-13}$.They are of two types:

a.) Liquefied gases propellant

b.) Compressed gases propellant

\section{Liquefied gases propellants:}

They are gases than exist liquid under pressure. The product is used up as the valve is opened, some of the liquid propellant turns to gas and keeps the head space full of gas.

\section{Types of propellant:}

\section{Chlorofluorocarbon Propellants}

Propellants are chemical inert, lack of toxicity, flammability. In recants years, they are very commonly used but now a day's their uses have been declined. Their advantages is that they have a lack of toxicity and non flammable. 


\title{
Hydrocarbons propellants
}

They are a low toxicity and non reactivity is the characteristic of hydrocarbons propellants allowing them to be used as the propellant. Hydrocarbons are used in the preparation of water based aerosols are they are not susceptible to hydrolysis due to the absence of chlorine. They are immiscible with water. Their advantages is that they are excellent solvent but there disadvantages is that they are flammable and explosiveness. Use of vapour tap valve reduces flammability. ${ }^{14}$

\section{Compressed gas propellants:}

Compressed gas like nitrogen, carbon dioxide as propellants dispenses product in the form of fine mists, foam or semisolid. It produces fairly wet sprays and the forms are not as stable as produced by the liquefied gas propellant. These propellants occupy the head space above the liquid in the can and when aerosol valve is opened the gas "pushes" the liquid out of the can.

\section{CONTAINERS}

Aerosols container to be selected should be able to withstand high pressure 140 to $180 \mathrm{psig}$ (per square inch guage) at $130^{\circ} \mathrm{F}$. Also, the cost, compatibility of the material with the formulation is to be considered. Containers are of different-2 types who are as follows:

\section{Containers}

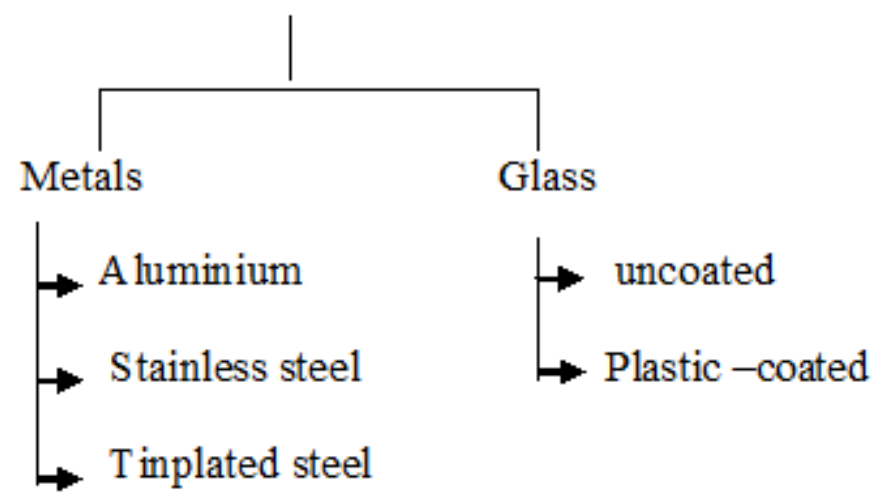

\begin{abstract}
Aluminium: The aluminium containers are light weight and are less prone to corrosion than other metals. Aluminium is used in metered dose inhaler (MDIs) and many topical aerosol. Vinyl or phenolic resins coatings are done on aluminium containers to reduce the interaction between the aluminium and the formulation. The container available in sizes ranging from 10 $\mathrm{ml}$ to $1,000 \mathrm{ml}$.
\end{abstract}

Stainless steel: They are extremely strong container, resistant to many material and no needs for internal coating but they are very expensive or costly.

Tinplated steel: It consists of a sheet of steel plate and this sheet coated with tin. The coated sheet is cut into 3 pieces (top, bottom, body) attached to body by soldering. Oleoresin, phenolic, vinyl coatings are used as coating materials. Tin plated steel containers are used in topical aerosols. 
Glass containers: There are large no. of aesthetic value and these containers are limited to the products having pressure (33 psig) and used in lower pressure and when low amount of propellant are in use such as if the pressure is less than 25psig.In order to protect the glass containers against breakage due to high pressure, it is to be coated with plastic coating in two layers. ${ }^{15}$

\section{VALVES}

The primary function of the valve is to regulate the flow of the therapeutic agent and propellant from the container. Valves are easy to open and close \& shown in Figure 2. They are capable of delivering the content in desired form such as spray, foam stream etc. Valves are of two types:

1. Metering valves

2. Continuous spray valves

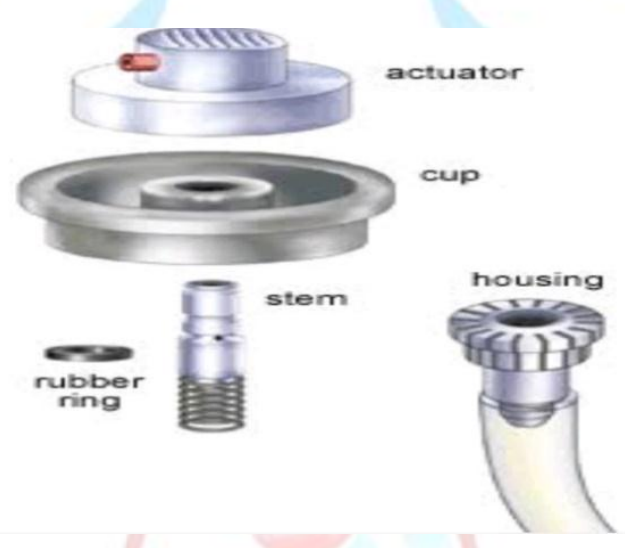

Figure 2: Aerosols valves components

Actuators: These are designed buttons which helps in delivering the drug in desired form i.e. spray, wet stream, foam or solid stream. The actuator contains orifices of varying size and shapes as well as the expansion chamber which determines the type and quantity of propellant used, actuator design.

Stems: The actuator is supported by the stem and the formulation is delivered in the proper form to the chamber of the actuator by the stem. It is made up of nylon, and stainless steel.

Gasket: The stem and valve are placed tightly in their place by the gasket and the leakage of the formulation is prevented by gasket.

Spring: The gasket is held in its place by the spring and also helps to keep the valve in closed position when the pressure is released upon actuation of the formulation.

Mounting cup: The mounting cup is generally made up of aluminium which serves to place the valve position and attached to the aerosol container. It may be coated with an inert material such as vinyl coating as it prevents any interaction with the contents also corrosion of aluminium is prevented. ${ }^{12-15}$ 


\section{APPARTUS USED OF PHARMACEUTICAL AEROSOL:}

- Pressure filling apparatus

- Cold filling apparatus

- Compressed gas filling apparatus

\section{Pressure filling apparatus:}

Pressure filling apparatus consists of metering burette capable of measuring the amount of propellant to be filled to the aerosol container. The propellant is to be added through the inlet valve present to the bottom of the valve under its own vapour pressure. A cylinder of nitrogen or compressed gas is attached to the top of the valve and the pressure of nitrogen causes the propellant to flow to the container through the metering burette.

\section{Cold filling apparatus:}

It consists of an insulated box fitted with copper tubing. The insulated tubing are filled with dry ice copper acetone. The copper tubing increase the surface area and cause faster cooling

\section{Compressed gas filling apparatus:}

A compressed gas propellant is used. As the compressed gas is under high pressure is reduced by pressure reducing valve. A pressure of 150 pounds per square inch gauge is required to fill the compressed gas propellant in the aerosol container. ${ }^{2,8}$

\section{EVALUATION PARAMETERS OF PHARMACEUTICAL AEROSOLS:}

\section{Flammability and combustibility}

It includes flame projection and flame projection.

1.) Flash point: Tag open cup apparatus is the standard test apparatus. The aerosol product is chilled to a temperature of about- $25^{\circ} \mathrm{F}$ and transferred to the test apparatus. The temperature of the test liquid is increased slowly.

2.) Flame extension, flame projection: The aerosol product is sprayed to an open flame for about 4 second and the extension of the flame is measured with the help of ruler.

\section{Physiochemical Characters}

- Vapour pressure

- Density

- Moisture content

- Identification of propellants

- Concentrate-propellant ratio

\section{Performance}

- Aerosol valve discharge rate: An aerosol product of known weight is taken and its content is discharged using standard apparatus for a given period of time. The container 
is reweights. Then the change in weight per time dispensed is the discharged rate. The discharge rate can also be expressed as grams per second.

- Spray pattern: The method involves the impingement of sprays on a piece of paper that has been treated with dye- talc mixture. It given a record of the sray pattern.

- Dosage with metered valves: The doses are dispensed into the solvents pr into the material that absorb the active material. The assay of the solution gives the amount of active ingredient present. The container is then reweighed and the difference in weight divided by the number of doses dispensed gives the average doses. The process is repeated and the results are compared.

- Net contents: The tared cans are placed onto the filling line are weighed, the difference in weight is equal to the net contents.

- Foam stability: The life of a foam ranges from a few seconds to one hour or more depending on the formulation The methods which are used to determine the foam stability include visual evaluation, time for a given mass to penetrate the foam, time for a given rod that is inserted into the foam to fall and rotational viscometer.

- Particle size determination

- Leakage

Biologic characteristics: Therapeutic activity and toxicity are considered in biologic testing. ${ }^{8}$ QUALITY CONTROL OF PHARMACEUTICAL AEROSOLS:

Quality control of pharmaceutical aerosol includes the testing of propellant, valves, actuator and dip tubes, container, weight checking, leak testing and spray testing.

Propellant: Their test includes:

1.) Identification of two or more blends of propellants by gas chromatography.

2.) Purity of the propellants is checked by moisture, halogen and non volatile residue determination.

\section{Valve, dip tube and actuators:}

Both physical and chemical examinations are done. Their testing procedures are:

- Take 25 valves and placed on suitable container.

- The container is filled with specific test solution.

- A button actuator with 0.02 inch orifice is attached $t$ the valves.

- The filled container is placed in a suitable atmosphere at a temperature of $25 \pm 1^{0} \mathrm{C}$.

- When the product has attained the temperature of $25 \pm 1^{0} \mathrm{C}$, the filled containers are actuated to fullest extent for 2 seconds.

- This procedure is repeated for a total of 2 delivered from each 25 test units. ${ }^{19}$ 


\section{Containers:}

Containers are examined for defects in linings. Quality control include degree of conductivity of electric current as measure of exposed metals. Glass containers examined for laws.

\section{Weight checking:}

It is done by periodically adding empty tared containers to filling lines which after filling with product concentrate are removed and reweighted.

\section{Leak test:}

It is done by measuring the crimps valve dimension and comparing. Final testing of valve is done by passing filled containers through the water bath. ${ }^{8}$

\section{CONCLUSION}

Aerosol is very useful for respiratory and asthma like diseases and they are directly to use to affected area and they are free from all contamination. As chlorofluorocarbon (CFC) propellants cause ozone depletion, they are being replaced with acceptable hydro fluoro carbon (HFC) propellants. Some of its advantages include the possibility of directly targeting the drug to the site of action and also reduction of systemic side effects etc. so they are used for a wide range of application in the treatment of asthma, chronic obstructive pulmonary diseases (COPD).

\section{REFERENCES}

1. Lachman L, Liberman HA, Kanie JL. The theory and practice of industrial pharmacy. $3^{\text {rd }}$ ed., India varghese publishing house; 1976: 589-618.

2. Pokar HG, Patel KR, Patel NM. Review on: Pharmaceutical aerosol. International Pharmaceutical science. 2012; 2: 58-66.

3. Telko MJ, Hickey AJ. Dry powder inhaler formulation. Respiratory care. 2005; 50: 120927.

4. Newman SP. Principle of Metered Dose Inhaler Design. Respiratory Care. 2005; 50: 1177-90.

5. Clark AR. Medical aerosol inhalers- Past, present and future. Aerosol Sci Technol. 1995; 22: $374-391$.

6. David AE, Abdelaziz BJ, Robert L. Recent advances in pulmonary drug delivery using large, porous inhaled particles. J Appl Physiology.1998; 85: 379-385.

7. Aulton ME. Pharmaceutics - The science of dosage form design. $2^{\text {nd }}$ ed., New York: Churchill Livingstone; 2002: 473- 88.

8. Lahkar S. An Overview on: Pharmaceutical Aerosols. International Research journal of pharmacy. 2012; 3: 68-75. 
9. Miller WF. Aerosol therapy in acute and chronic respiratory disease. Arch Intern Med. 1973; 131: 148-55.

10. Yu G, Zhang Z, Lessmann R. Fluid flow and particle diffusion in the human upper respiratory system. Aerosol Science and Technology. 1998; 28:146-158.

11. Rubin BK, Fink JB. Optimizing Aerosol Delivery by Pressurized Metered- Dose Inhalers. Respiratory Care. 2005; 50: 1191-1200.

12. Hindle M, Duncan AG, Chrystyn H. A Study Using a Dry Powder Inhalers Are Bioequivalent to Metered-Dose Inhalers. Chest .1995; 107: 629- 633.

13. Stephen WS, Charles GT. The History of Therapeutic Aerosols: A Chronological Review. J Aerosol Med Pulm Drug Deliv. 2017; 30: 20-41.

14. Gandevia B. Historical review of the use of parasympatholytic agents in the treatment of respiratory disorders. Postgrad Med J. 1975; 51: 13-20.

15. Shehata M. History of inhalation therapy. Internet J Health. 2008; 9: 1-9.

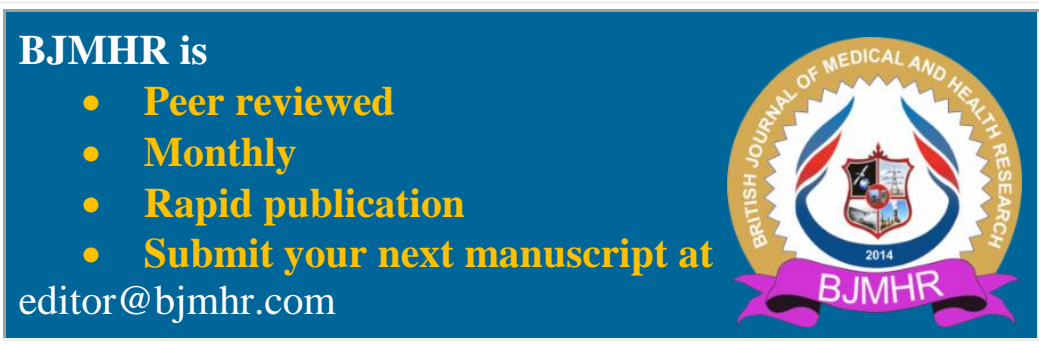

